\title{
Educating Leaders within the Context of an Inclusive Education Reform Agenda
}

\author{
Anastasia Liasidou, Androniki Antoniou \\ European University Cyprus European University Cyprus
}

\begin{abstract}
The quest for inclusive education necessitates a systemic process of initiating school reforms in order to create quality, participatory and socially just educational communities for learner diversity. Head teachers' role is considered as being crucial in this process, for they are expected to lead transformative changes to challenge the status quo, and to mobilize contextual struggles for the realization of an inclusive discourse. To this end, head teachers need to be afforded relevant professional development opportunities to catalyze changes commensurate with the principles of inclusion and social justice. The aim of the article is to explore the extent to which Cypriot head teachers are institutionally and professionally empowered to effect transformative changes under the light of current governmental rhetoric on the necessity to create 'humane and democratic schools' for learner diversity.
\end{abstract}

\section{Introduction}

Inclusion has become a globally mandated education policy imperative that envisages creating effective and socially just learning communities for learner diversity Even though inclusion starts with disability, it never ends with it as it extends to include other markers of difference linked to ethnicity/race, socio-economic background and so on [8]. Hence, particular emphasis is also given to the ways in which disability intersects with other sources of social disadvantage with a view to introducing a systemic approach to meeting the needs of disabled individuals [17].

Ainscow et al. explain the difference between "narrow" and "broad" definitions of inclusion [1]. On the one hand, the narrow definition of inclusion concentrates on specific groups of individuals, who have certain common characteristics, with particular reference to students with special educational needs and/or disabilities. On the other hand, the broad definition of inclusion, goes beyond issues of disability and concentrates on learner diversity that consists of distinct groups of students; namely looked after children, children from minority ethnic, faith and linguistic groups, gifted and talented children and so on. In this taxonomy, it is useful to add another conceptual strand; the "intersectional" dimension of inclusion that is concerned with the ways in which disabled students experience multiple and intersecting forms of disadvantage on the basis of their ethnic, racial, linguistic, social class and so forth characteristics [9].

This is a frequently neglected dimension that needs to inform debates on the ways in which a social justice framework can be applied to special education and inclusive practices [6]. Equality measures frequently tend to focus on one marker of difference while ignoring the intricately complex ways in which disability, race, class and other sources of social disadvantage interrelate and contribute to intersectional forms of discrimination and oppression.

Article 24 of the United Nations Convention on the Rights of Persons with Disabilities (UNCRD) stipulates the necessity to foster 'an inclusive education system at all levels' so that '( $p$ )ersons with disabilities are not excluded from the general education system on the basis of disability' (Article 24/a). Disability is defined as 'an evolving concept' that is the outcome of the interaction of a person's impairment with institutional and environmental barriers that undermine their full and equitable participation in social and educational domains [40]. The Convention also advances an intersectional understanding of disability and special educational needs (Articles 6 and 7); an issue that has implications for introducing equality measures intended to alleviate the multiple sources of social and educational disadvantage that have an adverse effect on disabled people's lives and educational trajectories. Based on an intersectional perspective, the notion of disability is re-conceptualized and redefined as a matter of human rights and social justice. This proposition necessitates shifting the focus from an individual pathology to an organizational pathology approach to disability; the aim being to mobilize wider institutional and ideological reforms to implement inclusion. That said, schools are transformed into critical sites in addressing the accumulative and overlapping sources of social disadvantage experienced by disabled students.

In light of legal and policy developments with regard to disability rights, it is necessary to put a more pronounced emphasis on issues of social justice and inclusion [6]; [24]; [28] with the aim of ensuring the equitable and nondiscriminatory participation of disabled individuals in all aspects of educational and social domains. The republic of Cyprus, as a signatory member, is obliged to abide by the 
stipulations of the Convention with a view to effecting radical changes to reinstate and safeguard disabled people's rights and entitlements.

In terms of disability rights in education, the introduction of the New National Curriculum (NNC) (MOEC 2010) has placed a more pronounced emphasis on creating 'democratic and humane' schools, while the notion of social justice is extensively cited throughout the document. Even through the notion of inclusion is not explicitly mentioned, the NNC is informed by concerns to create participatory and socially just educational communities for learner diversity, and concomitantly, highlights the importance of taking a broader view on understanding and dealing with educational failure. It is acknowledged that the notion of 'diversity' should be considered an endemic and valued aspect of human experience, while educational differentiation should be firmly embedded in pedagogical discourse so as to respond to learner diversity in effective and nondiscriminatory ways. Central to the process of transformative change is, according to the NNC, the importance of providing professional development opportunities to educators so as to be empowered to implement the envisaged reforms. Educational professionals need to get acquainted with the theoretical and action oriented parameters of an inclusive educational reform agenda predicated on the principles of social justice, democracy, and equality of opportunity [3], [32].

\section{Educating leaders for social justice and inclusion}

In recent years, there has been an enhanced interest in theorizing the necessity to incorporate a social justice discourse in school reforms concerned with providing more effective and equitable forms of education for learner diversity [5]; [14]; [35]; [39]. The notion of leadership has been linked to attempts to initiate inclusive education reforms to foster socially just and equitable learning communities [15], [16], [25]; [31], [39].

Leadership for social justice envisages transformative changes geared towards questioning and destabilizing power inequities, social hierarchies and discriminatory regimes that oppress disenfranchised groups of students. Current schooling acts as an exclusionary political site that regenerates and perpetuates social and cultural inequities affecting a great percentage of the student population [18]. A social justice discourse in educational leadership can foreground the ways in which power, domination and privilege collude towards essentializing difference in order to safeguard the institutional and ideological status quo.

Educational leadership is embodied in the role of educational professionals, who need to be empowered to become agents of transformative change within their contexts of practice [21]. Research on leadership for social justice has advanced discussions about the ways in which school leaders should be educated in order to be in a position to bring about transformative changes geared towards more socially just forms of teaching and learning [12]; [11]; [27].

The article suggests that leadership for social justice can be instrumental in empowering head teachers to redefine and reconceptualise their role as agents of change, and to act upon the transformative potential of professional praxis to challenge curricula and instructional injustices, and to mobilize inclusive education reforms. Leadership for social justice epitomizes educational professionals' commitment to redressing power imbalances and social hierarchies that create inferior and subjugated "student subjects" on the grounds of varied bodily, psychological and cognitive differences. Towards this end, school leaders should become "social justice workers committed to citizenship, ethics, and diversity" [27].

That said, professional development initiatives for school leaders must be informed by concerns about social justice, democracy, equity and diversity so as to enable them to understand the ways in which certain groups of students experience oppression and social disadvantage on the basis of their alleged deviation from normative corporeal, ethic, cultural, linguistic and so on norms [41]. Hence, it is imperative that a social justice discourse is embedded in all compulsory school leadership professional development programs [33].

Capper et al. suggest three conceptual pillars against which educational leaders' preparation programme should be predicated [6]. The first pillar is concerned with enhancing participant's critical consciousness, while the two others concentrate on instilling specific knowledge and skills so as to provide theoretical and action oriented tools for mobilizing socially just changes. The notion of social action implies potential for agency in promoting transformative change.

According to Hackman, a firm commitment to social justice necessitates that concerns about social justice "move beyond being buzzwords and instead become part of the lived practice in the classroom" [11]. This process entails head teachers' ability to generate and adopt pedagogical practices that:

take into account and are responsive to students' disparate lived experiences, their unequal material and social realities, and their diverse needs - and that, ideally, shape the curriculum, educational strategies, relationships among members of the school community, and create an inclusive learning environment [35].

In light of the principles enshrined in the official rhetoric, along with the immense importance attributed to the necessity of incorporating a social 
justice dimension in head-teachers' roles and professional development programs, the research aims to problematize head teachers' existing preparation programmes, which subordinate the ethical and value-based dimensions of professional praxis [2], and undermine head teachers' significant role in promoting an egalitarian and a social justice discourse in education policy and practice [4]; [36].

Even though the notion of educational leadership is not only embodied in the role of head teachers, as it also extends to include various forms of distributed leadership [13]; NCSL, 2004), the research concentrates on head teachers' leadership role. The data derives from a larger project on inclusive leadership [22], while the empirical part of this particular strand of research draws on interviews from 13 primary school head teachers and two officials seconded at the Pedagogical Institute, who are responsible to organize, manage and deliver professional development programs for educational professionals, A non-probability and, in particular, a purposive sample was used while all ethical considerations have been adhered to [7].

\section{Analysis and Discussion}

\subsection{Educating leaders for inclusion}

As a first step in order to collect empirical data, it was necessary to contact the Ministry of Education and Culture and the Pedagogical Institute, which is the official body for delivering professional development programs to educators, in order to gain access to the target population. When we explained that the aim and the scope of our research agenda was concerned with exploring professional development opportunities of head teachers within the context of an inclusive education reform agenda, the immediate response was that head teachers have many other responsibilities and issues to deal with and as a result, the topic under consideration was not considered a matter of major concern.

While interviewing the two incumbents at the Pedagogical Institute about the professional development opportunities available for head teachers, it became evident that interviewees were very little informed about the theoretical, policy and pedagogical implications of inclusion. Nevertheless they were very eager to provide information on available professional development opportunities, and they showed genuine interest in getting information about the aims and the theoretical underpinnings of our research agenda.

The two officials pointed out that head teachers' training programs are currently under review and subject to certain changes, but these changes are not related to issues of inclusive education or even integration. Although the consultation process for these changes included the views of several head teachers, who participated in previous professional development programs, these head teachers did not articulate the need to include these issues in head teachers' training. These findings are incompatible with the findings of our study whereby the head teachers interviewed expressed the view that training on these issues should be central to any professional development initiatives. Perhaps, the head teachers in our study expressed this view because this was the topic of our research agenda.

Some of the reported available professional development programs are concerned with the implementation of the Special Educational Law, the assessment procedures and the special educational needs referrals, without giving any consideration to the theoretical and value-based underpinnings as well as the plethora of problems of the current Special Education Law [20]. Issues related to disability rights, diversity, social justice and equality of opportunity are blatantly absent while the language and nomenclature used are commensurate with a deficit-oriented approach to difference and diversity on the grounds of disability and special educational needs. It is no coincidence then, that head teachers frame attempts to enhance the presence and participation of disabled students in mainstream schools against a special education perspective

This deficit oriented perspective is manifested in another available professional development course that is concerned with 'The management of serious problematic situations of students'. As the title and the content of the module suggest, social, emotional and behavioral difficulties (SEBD) are addressed through a mono-dimensional approach focused on specific conditions or syndromes that give rise to individual pathology assumptions and practices. Educational professionals are presented with this reductionist perspective, which ignores the host of contextual and situational considerations that contribute towards creating or exacerbating students' SEBD [10]. By excluding this significant dimension of SEBD, the role of schools and educational professionals in addressing these issues is downplayed on the grounds of an individual perspective in need of specialist and diagnostic interventions [23].

Slee is critical of the propagation of books, and by implication of professional development programs, which are supposed to give teaching recipes (what he calls education Do-It-Yourself manuals) [37]. The adoption of such a limiting perspective, encourages educators to 'eschew analysis' and to 'forfeit the educational potential to the allure of quick fixes for the symptoms of education in a complex world' ( $p$. 2 ). Within the context of inclusion, students' needs should be addressed through the lens of social and organizational pathology that adversely affect students' emotional stability and educational ability. Without ignoring the ways in which individual 
characteristics interact with the wider societal context, inclusion gives particular prominence to the latter to advance new theorizations of student identities.

\subsection{Inclusive leadership and transformative pedagogical action}

Data derived from head teachers' interviews suggest that the notion of inclusion constitutes an 'unknown theoretical and policy territory', while also documenting the fact that all available professional development programs are largely informed by a special education imperative. Far from having any professional development opportunities pertaining to the realization of an inclusive discourse, head teachers articulated the inadequate forms of professional development opportunities afforded to them, even when they are first promoted to headship. In terms of the latter, head teachers unanimously reported that the majority of their time is spent on managerial issues while they have very little time to concentrate on the pedagogical dimensions of their leadership role. As the interview extracts suggest, head teachers have very little time to visit classrooms, to evaluate the process teaching and learning so as to enable their schools to become adept at dealing with the challenges posed and the possibilities ensued by the increasing diversification of student population [34]; the aim being to improve the learning experiences and educational chances of all students irrespective of their biological attributes, developmental trajectories and lived experiences.

Head teachers also reported that even in cases where certain students are identified as being in need of additional forms of educational provision and support, there are huge delays in contacting other agencies such as the Educational Psychology Service, Welfare Services and so on. In this way, head teachers and schools cannot assume an active role in ensuring that students' needs are dealt with through the lens of an intersectional perspective [17].

Moreover, with regard to the scant professional development opportunities afforded to them in general as well as in more specific terms related to disability rights and inclusive education, head teachers criticize the excessively theoretical character of these professional development courses and their failure to forge links with educational praxis. According to Temple \& Ylitalo practical experience is considered as the most important learning device in order to instill and maximize leadership abilities. This is especially true, in the context of inclusive leadership whereby it is crucially important to create 'thinking practitioners' [30] so as to mobilize forms of socially just pedagogical activism [5]. This kind of activism necessitates imparting relevant evidence-based knowledge and cultivating specific skills for instigating transformative change. Professional activism constitutes an important dimension of raising educational leaders' critical consciousness with regard to their emancipatory role in redressing inequalities of power and oppressive regimes.

\section{Conclusions}

The article has been concerned with the relationship between leadership, social justice and inclusion in order to discuss the ways in which the role of head teachers needs to be reconfigured in alignment with the demands of a social justice reform agenda within the context of inclusion. The notion of leadership epitomizes potential for transformative action, with a view to creating socially just ways of thinking and acting to ameliorate the intersectional forms of disadvantage experienced by disenfranchised groups of students.

Notwithstanding its rhetorical appeal, the process of creating a 'human and democratic' school as envisaged in the NNC, runs the danger of becoming a cliché unless it is linked with professional activism embodied in critical forms of educational leadership. Central to this process, is the necessity to reconfigure professional roles and relationships so as to catalyze the process of transformative change. Even though the notion of leadership is not limited to the role of head teachers, the latter are recognized as being important agents for mobilizing socially just reforms. Professional development for social justice and inclusion is crucial in empowering head-teachers to become agents of change, and to galvanize the emancipatory potential of their professional praxis to promote equitable and socially just forms of provision.

\section{References}

[1] Ainscow, M., Booth, T., Dyson, D. (2006). Inclusion and the standards agenda: negotiating policy pressures in England. International Journal of Inclusive Education 10 (4-5), 295-308.

[2] Allan, J. (2005). Rethinking Inclusive Education: The Philosophers of Difference in Practice. Dordrecht: Springer.

[3] Armstrong, F., and L. Barton. 2007. "Policy, Experience and Change and the Challenge of Inclusive Education: The Case of England." In Policy, Experience and Change: Cross- Cultural Reflections on Inclusive Education, edited by L. Barton and F. Armstrong. Dordrecht: Springer.

[4] Bringhouse, H. 2009. "Educational Equality and School Reform." In Educational Equality, edited by G. Haydon, 15-68. London: Continuum.

[5] Brown, K.M ( 2004) Leadership for Social Justice and Equity: Weaving a Transformative Framework and 
Pedagogy. Educational Administration Quarterly 40, (1) 77-108.

[6] Capper, C. A., Theoharis, G., \& Sebastian, J. (2006). Toward a framework for preparing leaders for social justice. Journal of Educational Administration, 44(3), 209224.

[7] Cresswell, W. J. (2012). Qualitative Inquiry and Research Design: Choosing Among Five Approaches. Sage.

[8] Goodley, D. 2011. Disability Studies. an Interdisciplinary Introduction. London: Sage.

[9] Goodley, D. and Runswick-Cole K. (2011). Problematising policy: conception of <child>, <disabled> and <parents> in social policy in England. International Journal of Inclusive Education, 15(1), 71-85.

[10] Graham, L. (2005). The Incidental "Other": A Foucaultian interrogation of educational policy effects. In Proceeding American Educational Research Association (pp. 1-22). Montreal.

[11] Hackman, H.W (2005): Five Essential Components for Social Justice Education, Equity \& Excellence in Education, 38:2, 103-109.

[12] Guyton, E (2000): Social Justice in Teacher Education, The Educational Forum, 64:2, 108-114

[13] Harris, A. (2008). Distributed School Leadership: Developing Tomorrow's Leaders, Oxon: Routledge.

[14] Jean-Marie, Normore, \& Brooks, (2009). Leadership for Social Justice: Preparing 21st Century School Leaders for a New Social Order. Journal of Research on Leadership Education, 4(1), 1-31.

[15] Kugelmass, J. 2003. Inclusive Leadership; Leadership for Inclusion. Nottingham: NCSL.

[16] Kugelmass, J., and M. Ainscow. 2004. "Leadership for Inclusion: A Comparison of International Practices." Journal of Research in Special Educational Needs 4 (3): 133-141.

[17] Liasidou, A (2013): Intersectional understandings of disability and implications for a social justice reform agenda in education policy and practice, Disability \& Society, 28(3) 299-312

[18] Liasidou, A. (2012) Inclusive Education, Politics and Policymaking. London: Continuum

[19] Liasidou A. (2011) Special Education Policymaking; A discursive analytic approach Educational Policy, 25(6) 887-907

[20] Liasidou, A. (2008) Critical Discourse Analysis and Inclusive Educational Policymaking: The power to exclude, Journal of Education Policy, 13(5), 483-500.

[21] Liasidou, A \& Svensson, C (2013): Educating leaders for social justice: the case of special educational needs coordinators, International Journal of Inclusive Education, DOI: $10.1080 / 13603116.2013$.

[22] Liasidou, A. and Antoniou, A., (2013) A special teacher for a special child? (Re)considering the role of the special education teacher within the context of an inclusive education reform agenda. European Journal of Special Needs Education http://dx.doi.org/10.1080/08856257.2013.820484

[23] Lloyd, C. (2008). Removing barriers to achievement: A strategy for inclusionor exclusion? International Journal of Inclusive Education, 12, (2), 221-236.

[24] Marshall, C., \& Olivia, M. (2006). Leadres for social justice: Making revolutions in education. Allyn \& Bacon.

[25] Mayoretz, D., and C. Weinstein. 1999. "Sources of Leadership for Inclusive Education: CreatingSchools for all Children." Educational Administration Quarterly 35 (3): 423-449.

[26] Ministry of Education and Culture(2010) Thee New National Curriculum. MOEC; Nicosia

[27] Mullen, C \& Jones, R (2008): Teacher leadership capacity-building: developing democratically accountable leaders in schools, Teacher Development, 12:4, 329-340.

[28] Normore, A. H. (2008). Leadership for social justice: Promoting equity and excellence through inquiry and reflective practice. Charlotte, NC: Information Age.

[29] Norwich, B. (2010) A response to special educational needs: A new look. In L Terzi,

(Ed.), Special educational needs. A new look (pp. 47-113). London: Continuum.

[30] Rayner, S. (2009). Educational diversity and learning leadership: a proposition, some principles and a model of inclusive leadership? Educational Review, 61(4), 433-447.

[31] Reihl, C. J. (2000). The principal's role in creating inclusive schools for diverse students: a review of normative, empirical and critical literature on the practice of educational administration. Review of Educational Research, 70(1), 55-81.

[32] Rioux, M. (2002). Disability, citizenship and rights in a changing world. In C. Barnes, M. Oliver, \& L. Barton (Eds.), Disability studies today (pp. 210-227). Cambridge, UK: Polity Press.

[33] Rodríguez, A. M., Chambers, V. T., González, L. M., $\&$ Scheurich, J. J. (2010). A Cross-Case Analysis of Three Social Justice-Oriented Education Programs. Journal of Research on Leadership Education, 5( 3.5), 138-154.

[34] Ryan, J. 2006a. Inclusive Leadership. San Francisco, CA: Jossey-Bass.

[35] Shields, M. C. (2009). Trasformative Leadership: A Call for Difficult Dialogue and Courageous Action in Racialised Contexts. ISEA, 37(3), 53-68. 
[36] Shields, C. (2004). Dialogic Leadership for Social Justice: Overcoming Pathologies of Silence. Educational Administration Quarterly, 40 (1), 109-132.

[37] Slee, R (2012) How do we make inclusive education happen when exclusion is a political predisposition? International journal of Inclusive EducationDOI:10.1080/13603116.2011.602534

[38] Theoharis, G. (2009). The School Leaders Our Children Deserve: Seven Keys to Equity, Social Justice, and School Reform. Teacher Collage Press.

[39] Theoharis, G., \& Causton-Theoharis, J. (2008) Creating inclusive schools for all students. The School Administrator, September, 24-30.

[40] UN-United Nations (2008). Convention on the Rights of Persons with Disabilities . New York: United Nations.

[41] Young, M. D., \& Brooks, J. S. (2008). Supporting graduate students of color in educational administration preparation programs: Faculty perspectives on best practices, possibilities, and problems. Educational Administration Quarterly, 44(3), 391-423. 